\section{Reaction time as a function of stimulus uncertainty on a single trial*}

\author{
ALBERT E. BARTZ \\ Concordia College, Moorhead, Minnesota 56560
}

In a discrete choice-reaction-time experiment, reaction times were measured between the onset of a light and the start of S's pencil toward that light. The reaction time of unpracticed Ss, not aware that their first "practice" trial was being measured, increased as a linear function of stimulus uncertainty. Since this occurred without any prior experience, the effect must have been due to S's set or expectancy regarding the nature of the future task, formed while the instructions for the task were being given.

The relationship between choice reaction time (RT) and the number of alternative stimuli was first noted by Merkel (1885), and was verified in a number of later studies. However, with the exception of Blank (1934), who postulated a logarithmic relationship, no quantitative theory emerged from these studies. It was not until the publication of Shannon's monograph (1949) that the theoretical framework existed for a precise formulation of the relationship between RT and the number of stimuli.

Hick (1952) proposed a model showing that RT is a linearly increasing function with $\log _{2}$ of the number of alternative equiprobable stimuli-that is, with stimulus uncertainty. Hick used from 2 to 10 small visual stimuli in a choice RT task, and required $\mathrm{S}$ to press a key corresponding to one of the stimulus lights. In several experiments, using either one or two Ss and thousands of trials, Hick found the now familiar relationship between RT and stimulus uncertainty.

This study of Hick's, along with those of Crossman (1953) and Hyman (1953), demonstrated that this relationship holds whethe: stimulus uncertainty is manipulated by varying the number of equiprobable alternatives or by varying either the probabilities of occurrence of each stimulus or the sequential dependencies among the stimuli.

The three studies cited above became the foundation for a host of studies performed, for the most part, within the last 10 years. Most of the studies reported that the shape of the function relating RT to the number of stimuli depends upon a large number of other RT characteristics-among them stimulus-response compatibility, amount of training, discriminability, payoffs, and

\footnotetext{
*The author expresses his appreciation to James Lee, Gary Hackney, and Charles Heuer for their assistance on this project. Portions of this paper were presented at the 1970 annual meeting of the Midwestern Psychological Association.
}

speed-accuracy sets. However, the relationship between $\mathrm{RT}$ and stimulus uncertainty remained a core concept in the analysis and explanation of the data, even though these variables often completely masked the relationship.

A few of the studies, however, failed to find evidence for such a relationship. When S's response consisted of the naming of Arabic numerals (Morin \& Forrin, 1962; Brainard et al, 1962), or eye movements to peripheral stimuli (Saslow, 1963), or when $E$ varied the probability of nonrepetition of a signal for a fixed number of signals (Kornblum, 1968), the increase in RT as a function of the number of stimuli did not occur.

Previous studies, without exception, have made use of practiced Ss-at least to the extent that Ss have made more than one responsc. In some studies each $S$ has responded in all of the experimental conditions, while in others he has made a number of responses, but only in one of the experimental conditions. The study of $S$ 's responses to a series of signals was necessary if the investigator was studying information transmission. 1

It would uppear that an additional test of the relationship between $\mathrm{RT}$ and stimulus uncertainty could be made by investigating $S$ 's response to a single event. I he iniormation measure under consideration is now $I=-\log p_{i}$, where $I$ is the information in a single event, and $p_{i}$ is the probability of occurrence of signal i. This would be a critical test if two requirements were met: (1) Ss must be unaware of stimuli other than those for which they are being tested, and (2) only their first response can be analyzed. The first requirement would prevent Ss from forming any kind of expectancy or set regarding the difficulty of their task relative to tasks involving fewer or greater numbers of stimuli. The second requirement, of course, would eliminate any cumulative effect that practice might have. The present experiment was designed to investigate the relationship between RT and stimulus uncertainty with these two requirements in mind.

\section{METHOD \\ Subjects \\ The Ss were 166 volunteers from the introductory psychology course at Concordia College.}

\section{Apparatus}

The apparatus consisted of a clear plastic panel $30 \mathrm{~cm}$ square which was placed flat on a table in front of $S$. At the left side of the panel was a lever where $S$ was instructed to hold a soft lead pencil. This lever was connected to a microswitch mounted beneath the panel. Beneath the right side of the panel were mounted eight flashlight bulbs with magnifying lenses (GE 112) that would project a spot of light $6 \mathrm{~mm}$ in diam on a sheet of paper that covered the panel. These lights were spaced $3 \mathrm{~cm}$ apart on an arc that was at a radius of $20 \mathrm{~cm}$ from the lever where the pencil was held. Four lights were above an imaginary line bisecting the panel at the lever, and four were below. For purposes of this discussion, the light farthest from $S$ is designated Stimulus No. 1, and the one closest to $S$ is No. 8 .

S's task was to draw a line as fast as possible from the lever to the spot of light on the right side of the paper. The onset of a light started a timer that stopped when $S$ left the starting position at the lever and began to draw a line on the paper. The paper also served to prevent $S$ from seeing the flashlight bulbs.

\section{Procedure}

The 166 Ss were assigned at random to one of the four experimental conditions of $2,4,6$, or 8 lights. The identity of the lights in each set is shown in Table 1 . Ss were instructed: "This is an experiment to see how fast you can move your hand when a light comes on. Hold this pencil against this metal stop. I will say 'ready' and then a light will come on over here. ( $E$ pointed at the approximate location where the stimulus lights would appear.) As soon as the light comes on, draw a line as fast as you can over to the light. The light will come on in one of these places. (At this point E flashed on each light in that S's condition for $1 \mathrm{sec}$ while $S$ watched.) There will be two practice trials before we begin. Are there any questions?"

The $E$ then gave the ready signal and approximately $1 \mathrm{sec}$ later the first stimulus light came on. The stimulus light on this first "practice" trial for all Ss was No. 4. Six additional trials were run, but the data are not reported here. The sheet of paper covering the panel was replaced after each $\mathrm{S}$. 
Table 1

Information ( $\left.I=-\log \mathrm{pj}_{\mathrm{j}}\right)$ and Stimulus Sets for the Four Conditions, Showing Means and Standard Deviations for Ss' First Trial

\begin{tabular}{lccccc}
\hline $\begin{array}{c}\text { Condi- } \\
\text { tion }\end{array}$ & $\begin{array}{c}\text { Infor- } \\
\text { mation }\end{array}$ & $\begin{array}{c}\text { Stimulus } \\
\text { Set }\end{array}$ & $\begin{array}{c}\text { Mean } \\
(\text { Msec })\end{array}$ & $\begin{array}{c}\text { SD } \\
\text { (Msec) }\end{array}$ & N \\
\hline 2 & 1.00 & 4,5 & 272 & 72 & 41 \\
4 & 2.00 & $3,4,5,6$ & 311 & 59 & 46 \\
6 & 2.58 & $2,3,4,5,6,7$ & 333 & 66 & 37 \\
8 & 3.00 & $1,2,3,4,5,6,7,8$ & 345 & 54 & 42 \\
\hline
\end{tabular}

\section{RESULTS}

Table 1 and Fig, 1 show the responses of the $S s$ in the four conditions to Stimulus No. 4 on their first "practice" trial. The data showed a statistically significant linear trend $[F(1,162)=31.2, p<.001]$; that is, the best-fitting straight line is statistically different from a zero slope. The deviation from linearity was not significant $[F(2,162) \approx 1]$.

\section{DISCUSSION}

On the basis of these results it seems apparent that the effect of stimulus uncertainty on RT is very persistent indeed, and RT behavior is highly sensitive to variations in information. Ss were operating without any knowledge of the total number of stimuli used in the experiment or the number of stimuli to which other Ss might be responding. In fact each S's only exposure to the number of stimuli in his own condition came during the instructions when each light of his stimulus set was flashed on for $1 \mathrm{sec}$ each. After the instructions were given, he saw only a blank sheet of paper.

A number of studies (e.g., Poulton, 1950; Bartz, 1966) have emphasized the importance of the set or expectancy of $S$ regarding the nature of the future task. In Poulton's study, Ss were asked to move a stylus in a pattern-tracing task. In one condition $S$ was instructed to trace a geometric pattern, while in the other condition he was to trace only the first leg of the complete pattern. Poulton found that when Ss were set for the complete pattern, it took about $25 \mathrm{msec}$ longer to begin to move the stylus than when they were set to make the simpler movement. In a similar study, Bartz (1966) asked Ss to respond to one of two lights by pressing a key with one hand. In one condition this constituted the entire task, while in the other condition this first response was followed by a response to another two-choice situation with the other hand. As expected, when Ss had only the single two-choice situation to respond to, their RTs were significantly faster than when their first response was to be followed by other responses with the opposite hand. Poulton (1950) commented on his results, "Present performance is always dominated by the subject's idea of the immediate future, by what he expects to happen, and by what he is trying to accomplish [p. 112]."

The present study certainly seems to link Poulton's concept of set with stimulus uncertainty, and it would appear that S's observation of the stimuli during the instructions prior to his first trial is a sufficient condition for demonstrating the effect of stimulus uncertainty.

\section{REFERENCES}

BARTZ, A. E. Reaction time and complexity of subsequent responses. Psychological Record, 1966, 16, 313-321.

BLANK, G. Brauchbarkeit optischer Reaktionsmessungen. Industrielle Psychotechnik, 1934, 11, 140-150. Cited by Hick, W. E. On the rate of gain of information. Quarterly Journal of Experimental Psychology, 1952, 4, 11-26.

BRAINARD, R. W., IRBY, T. S., FITTS, P. M. \& ALLUISI, E. A. Some variables influencing the rate of gain of information. Journal of Experimental Psychology, 1962, 63, 105-110.

CROSSMAN, E. R. F. W. Entropy and choice time: The effect of frequency unbalance on choice response. Quarterly Journal of Experimental Psychology, 1953, 5, $41-51$.

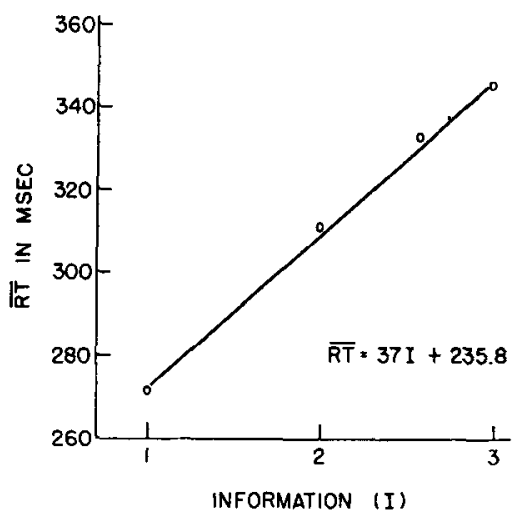

Fig. 1. Mean RT as a function of information.

HICK, W. E. On the rate of gain of information. Quarterly Journal of Experimental Psychology, 1952, 4, 11-26.

HYMAN, R. Stimulus information as a determinant of reaction time. Joumal of Experimental Psychology, 1953, 45, 188-196.

KORNBLUM, S. Serial-choice reaction time: Inadequacies of the information hypothesis. Science, $1968,159,432-434$.

MERKEL, J. Die zeitlichen Verhältnisse der Willensthätigkeit. Philosophische Studien, 1885, 2, 73-127. Cited by Hick, W. E. On the rate of gain of information. Quarterly Journal of Experimental Psychology, 1952, 4, 11-26.

MORIN, R. E., \& FORRIN, B. Mixing of two types of $S-R$ associations in a choice reaction time task. Journal of Experimental Psychology, 1962, 64, 137-141.

POULTON, E. Perceptual anticipation and reaction time. Quarterly Journal of Experimental Psychology, 1950, 2, 99-112.

SASLOW, M. G. Invariance of latency for saccadic eye movement to lateral displacement of a point of light, as a function of number and location of equally probable alternatives. Paper presented at the annual meeting of the Western Psychological Association, 1963.

SHANNON, C. E., \& WEAVER, W. The mathematical theory of communication. Urbana: University of Illinois Press, 1949. NOTE

1. The relationship between $\mathrm{RT}$ and stimulus uncertainty $\left(H_{S}\right)$ can be given by $R T=a+b H_{S}$. If the error rate is low, as it was in the studies cited, transmitted information $\left(\mathrm{H}_{\mathrm{t}}\right)$ is approximately equal to $H_{s}$. The information in a sequence of signals (Crossman, 1953) is

$$
H=-\sum_{i}^{n} p_{i} \log p_{i}
$$

(Accepted for publication April 24, 1970.) 